\title{
Anabases
}

ANABASES Traditions et réceptions de l'Antiquité

$23 \mid 2016$

Varia

\section{Mary P. NICHOLS, Thucydides and the Pursuit of Freedom}

Tiago da Costa Guterres

\section{(2) OpenEdition}

\section{Journals}

Édition électronique

URL : http://journals.openedition.org/anabases/5709

DOI : 10.4000/anabases.5709

ISSN : 2256-9421

\section{Éditeur}

E.R.A.S.M.E.

\section{Édition imprimée}

Date de publication : 2 mai 2016

Pagination : $327-328$

ISSN : 1774-4296

\section{Référence électronique}

Tiago da Costa Guterres, « Mary P. nICHols, Thucydides and the Pursuit of Freedom », Anabases [En ligne], 23 | 2016, mis en ligne le 02 mai 2016, consulté le 23 septembre 2020. URL : http://

journals.openedition.org/anabases/5709; DOI : https://doi.org/10.4000/anabases.5709

Ce document a été généré automatiquement le 23 septembre 2020.

(c) Anabases 


\title{
Mary P. NICHOLS, Thucydides and the Pursuit of Freedom
}

\author{
Tiago da Costa Guterres
}

\section{RÉFÉRENCE}

Mary P. NICHOLS, Thucydides and the Pursuit of Freedom

Ithaca (New York)-London, Cornell University Press, 2015, 208 p.

49 dollars/ ISBN 9780801453168

1 Selon Aristote, dans la Poétique, l'historien dit ce qui a eu lieu (1451 b4-6). On peut donc en déduire que, s'il s'est engagé à faire quelque chose, il s'agit essentiellement de dire les faits avec exactitude, comme l'emploi du substantif akribeia chez Thucydide semble le suggérer (I, 22). Partant de là, Mary Nichols cherche à présenter une autre facette de l'historien athénien, en explorant ce qu'a été son engagement pour la cause de la liberté. Dans son récit, des individus et des peuples considèrent la liberté comme un but ; tel est le cas pour les protagonistes de la Guerre du Péloponnèse, Athéniens et Spartiates, chacun à sa manière.

2 L'ouvrage comporte une introduction intitulée « Thucydides as Historian », qui présente avec clarté le sujet et résume les cinq chapitres (ou encore six, si l'on considère sa conclusion de seize pages). Le chapitre 1, "Periclean Athens and an image of freedom ", analyse la figure du Périclès thucydidéen et la vision de l'historien des possibilités et des limites de la liberté humaine. Le chapitre 2, "Athenian Freedom in the Balance Mytilene and Plataea ", concerne la politique athénienne immédiatement après la mort de Périclès et le débat autour du destin de Mytilène après sa prise. Comme ce débat met en scène, par comparaison, l'action politique de Sparte, le troisième chapitre, "Sparta, Brasidas, and the liberation of Hellas » étudie les traits du leader spartiate Brasidas, qui prend la tête d'une " croisade " pour la libération des cités soumises à Athènes. Les chapitres 4, "Sicily, Alcibiades and the liberation of Eros ", et 5, "Homecoming and freedom ", sont centrés sur la figure d'Alcibiade et sa place dans la réflexion de Thucydide sur la 
liberté : son soutien à l'expédition en Sicile, et ses efforts (c'est aussi le cas pour Nicias) pour rentrer chez soi. La conclusion, "Thucydides, an Athenian ", discute de la manière dont l'historien réconcilie le but d'écrire conformément à la vérité et sa condition d'Athénien.

3 Être libre signifie être autonome, ne pas se soumettre à d'autres peuples. Cependant, il ne s'agit pas seulement de ne pas être un esclave : il faut être libre dans sa propre cité. Cela dit, l'auteur examine dans son livre les acteurs de la Guerre du Péloponnèse tels qu'ils sont présentés par Thucydide, soit par leurs discours, soit par leurs actions pendant le conflit. Certains personnages ont une importance particulière dans l'ouvrage, comme Périclès, Cléon, Diodote, Braside, Nicias et Alcibiade. Le principal parmi eux est Périclès. Il est celui qui commande non par la force, mais par le discours, en gouvernant le peuple par la liberté (II, 65). Bien qu'il puisse être considéré comme la cause (aitia) de la guerre, il reste la meilleure option parmi des noms tels que Cléon, qui subvertit la distinction entre la persuasion et la violence, ou encore Alcibiade et Nicias, marqués par l'expédition désastreuse en Sicile. La supériorité d'Athènes par rapport à Sparte est aussi soulignée par l'historien, qui compare les faits accomplis par ces deux poleis en différentes circonstances. Par exemple, la manière dont Athènes agit contre Mytilène en contraste avec la manière avec laquelle Sparte agit contre Platées : aucun Spartiate ne montre de la sympathie pour les Platéens, au point de proposer un débat comme les Athéniens l'ont fait pour Mytilène. Bien que les deux poleis se battent pour la liberté, c'est le modèle athénien qui convient à Thucydide.

4 C'est à partir de la confrontation entre des discours et des actes dans le contexte de la Guerre que l'auteur cherche à situer Thucydide. Non seulement l'historien, mais aussi le citoyen (ou encore l'exilé), se montre préoccupé de sa cité. Ni postmoderne ni " scientifique ", Nichols considère l'historien athénien comme un auteur qui, malgré la recherche de la vérité, ne laisse jamais d'être un sujet ayant des conceptions politiques. À quoi cela aboutit-il ? Peut-être à une idée différente de la liberté selon qu'elle est comparée à l'idée de la liberté conçue par un simple citoyen en temps de guerre. Une double distance s'instaure, parce qu'il est historien et exilé en même temps. Bien qu'il prenne Périclès pour modèle, il ne s'agit pas de ne pas marquer des réserves. Son écriture de l'histoire est sa façon de manifester sa liberté en tant qu'Athénien. Son écriture est, comme dit Nichols, son homecoming.

Le livre est une lecture intéressante de Thucydide appréhendé autant comme historien que comme Athénien. Néanmoins, il est dommage que l'auteur se soit concentré sur les acteurs au point de ne pas explorer la question en termes d'historiographie grecque, en particulier en menant la comparaison avec Hérodote. Premièrement, parce que l'enquêteur d'Halicarnasse accorde dans son Enquête une importance particulière à la question de la liberté : le conflit qu'il raconte met en danger la culture grecque ellemême face à la menace perse. Deuxièmement, Nichols insiste sur le sens critique de Thucydide à l'égard de ses concitoyens qui célèbrent Harmodios et Aristogiton comme les meurtriers des tyrans. Cependant, l'auteur ignore le passage où Hérodote lui aussi met en question l'importance d'Harmodios et Aristogiton pour la liberté des Athéniens (VI, 123). Pour mieux comprendre le regard critique de Thucydide sur la tradition, il faudrait le situer dans son contexte historiographique.

6 L'ouvrage possède un index général. On regrettera que sa bibliographie réduite, de cinq pages, soit composée presque uniquement de textes en langue anglaise. 


\section{AUTEUR}

TIAGO DA COSTA GUTERRES

Universidade Federal

do Rio Grande do Sul (ufrgs)

tiagocguterres@gmail.com 